\title{
The Validity Of Linear Wave Theory In The Determination Of The Efficiency Of Submerged Breakwaters On Sloped
}

ElSadek Heikal

\begin{abstract}
The validity of linear wave theory in determining the efficiency of thin vertical submerged breakwater located on sloped beaches is analyzed using the Eigenfunction expansion method. The wave height is calculated shoreward and seaward the breakwater site with and without the breakwater model. The transmission coefficient and the wave height distribution around the breakwater were calculated for different beach slopes and incident wave field conditions. The theoretical results were compared with tlie experimental results carried out in a tilting wave flume having a variable speed wave generator. It is concluded that; the linear wave theory is valid only for intermediate waves run over a nearly steep beaches.
\end{abstract}

